\title{
The Mizoroki-Heck reaction with internal olefins: Reactivities and stereoselectivities
}

\author{
Yusei Nakashima ${ }^{[a]}$, Goki Hirata ${ }^{[a]}$,Tom D. Sheppard ${ }^{[b] *}$, and Takashi Nishikata ${ }^{[a] *}$
}

\section{Abstract:}

The Mizoroki-Heck $(\mathrm{M}-\mathrm{H})$ reaction is one of the most valuable reactions for functionalizin $\mathrm{C}-\mathrm{C}$ double bonds in the presence of a $\mathrm{Pd}$ catalyst. This protocol is suitable for the reaction of a $\mathrm{C}\left(\mathrm{sp}^{2}\right)$-halide with a terminal olefin to produce a trans-1,2disubstituted olefin. However, reports of the $\mathrm{M}-\mathrm{H}$ reaction of internal olefins are rare and impractical due to low reactivity of internal olefin and problem of product diastereoselectivity. In this review, we summarise $\mathrm{M}-\mathrm{H}$ reactions of internal olefins with arylor alkyl halides.

\section{Introduction}

The reaction of an organic halide and an olefin in the presence of palladium catalyst (or other transition metals) to produce a substituted alkene via oxidative addition, carbopalladation and $\beta-\mathrm{H}$ elimination is called the Mizoroki-Heck $(\mathrm{M}-\mathrm{H})$ reaction (Scheme 1) [1]. This incredibly useful reaction was discovered by Mizoroki[2] and Heck[3,4] independently. In 2010, Heck was awarded the Nobel prize in chemistry with Suzuki and Negishi[5] Almost half a century has passed since the $\mathrm{M}-\mathrm{H}$ reaction was discovered, but we can still see many reported new developments on the $\mathrm{M}-\mathrm{H}$ reaction today.

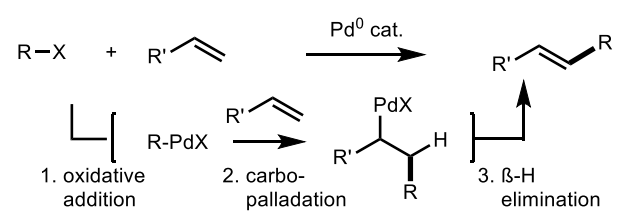

Scheme 1. The $\mathrm{M}-\mathrm{H}$ reaction

Although considerable progress on the chemistry of the $\mathrm{M}-\mathrm{H}$ reaction has been made, some issues remain unsolved. For example, terminal olefins (mono-substituted olefins) are excellent substrates for the $\mathrm{M}-\mathrm{H}$ reaction giving trans alkene products, whereas internal olefins (1,2-disubstituted olefins) show low reactivity and the products are often produced as mixtures of stereoisomers (Scheme 2).

[a] Mr. Yusei Nakashima, Dr. Goki Hirata, Prof. Dr. Takashi Nishikata Graduate School of Science and Engineering, Yamaguchi University 2-16-1 Tokiwadai, Ube, Yamaguchi, 755-8611, Japan

E-mail: nisikata@yamaguchi-u.ac.jp

[b] Prof. Dr. T. D. Sheppard

Department of Chemistry, University College London, Christophe Ingold Laboratories, 20 Gordon Street, London, WC1H OAJ, U.K.

E-mail: tom.sheppard@ucl.ac.uk

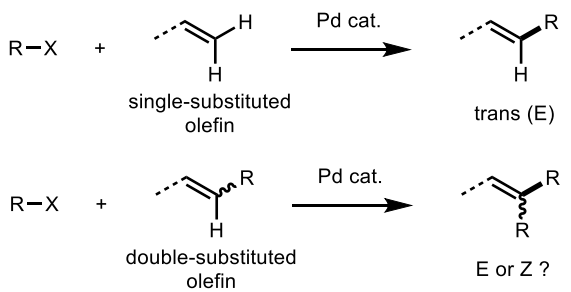

Scheme 2. M-H reaction with terminal or internal olefins

In order to predict the stereochemistry in the $\mathrm{M}-\mathrm{H}$ reaction of non-terminal olefins, a Newman projection is useful. When R$\mathrm{PdX}$ adds to a trans internal olefin, the carbopalladation intermediate $\mathbf{A}$ is obtained. After $\mathrm{C}-\mathrm{C}$ bond rotation of $\mathbf{A}, \beta-\mathrm{H}$ elimination from $\mathbf{B}$ occurs to give the $(E)$-product. Similarly, the $Z$-product is obtained from a cis internal olefin via rotamer $\mathbf{D}$. In most cases, the $\mathrm{M}-\mathrm{H}$ reaction with internal olefins produces a mixture of $(E)$ and $(Z)$ products even from a single geometrical isomer of substrate. This is because the Pd catalyst can enable isomerization of cis internal olefins to trans internal olefins [6]. However, most $\mathrm{M}-\mathrm{H}$ reactions of terminal dienes and 1-alkenyl halides in the presence of a $\mathrm{Pd}$ catalyst produce a single stereoisomer of the products, and do not suffer from stereoisomerization of the products [7]. In this short review, we will summarise a selection of examples of $\mathrm{M}-\mathrm{H}$ reactions of aryland alkyl halides or arylboron reagents with internal olefins.

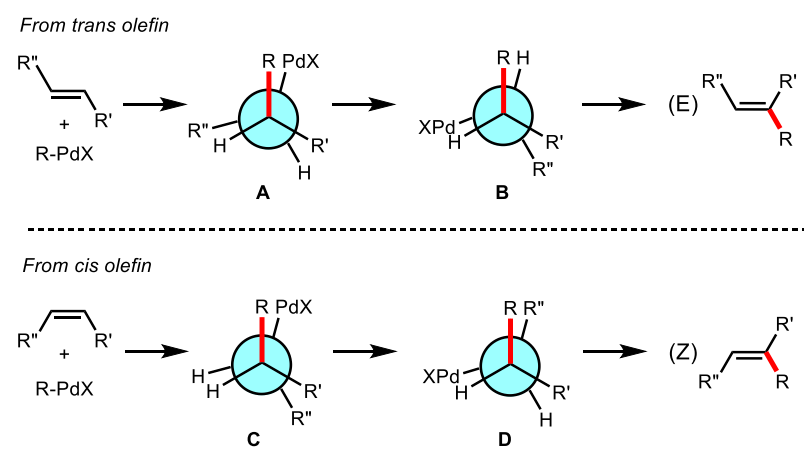

Scheme 3. Explanation of stereoselectivity in $\mathrm{M}-\mathrm{H}$ reaction 
Takashi Nishikata received his Ph.D. degree from Hokkaido University in 2005 under the supervision of Professor Norio Miyaura. He spent three years as a JST postdoctoral fellow in the same group. From 2008 to 2010 , he worked as a postdoctoral fellow at the University of California, Santa Barbara under the direction of Prof. Bruce H. Lipshutz. In 2010, he joined Prof. Hideo Nagashima's group as an assistant professor at Kyushu University. Since 2012, he has been an associate professor at Yamaguchi University.

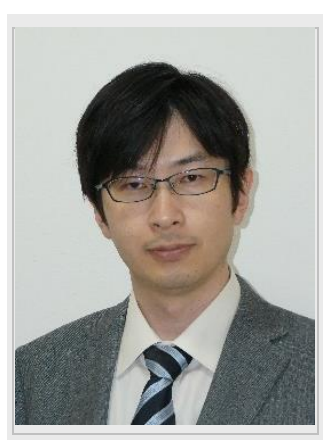

Goki Hirata received his Ph.D. degree from Nagasaki University in 2017 under the supervision of Prof. Masanari Kimura. He spent two years as a postdoctoral fellow at Ritsumeikan University (Prof Hiromitsu Maeda). Since 2019, he has been an assistant professor at Yamaguchi University.

Yusei Nakashima received a BSc degree from Yamaguchi University in 2019. Since 2019 , He has been a graduate student at the same university under the supervision of Prof. Takashi Nishikata.

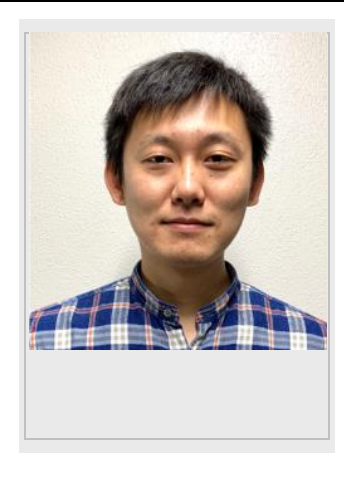

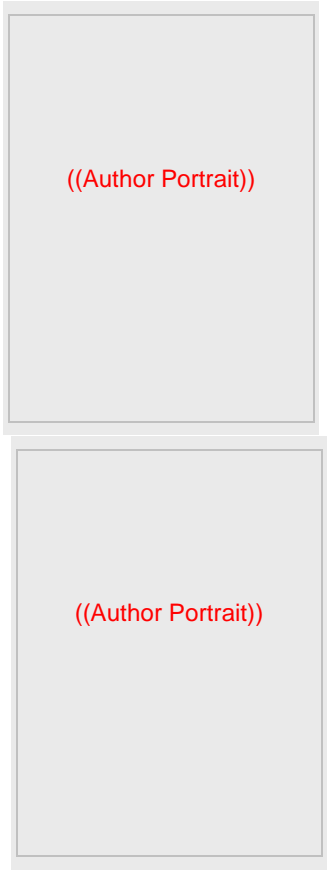

Tom Sheppard received his $\mathrm{PhD}$ degree from the University of Cambrdige in 2004 under the supervision of Professor Steven Ley. He carried out postdoctoral research with Professor William Motherwell at University College London from 2004-2007, before being awarded an EPSRC Advanced Research Fellowship and a lectureship at University College London to begin his independent research career. He was promoted to Reader in 2013, and since 2018, he has been a full professor of organic chemistry at University College London.

\section{2. $\mathrm{M}-\mathrm{H}$ reaction with internal olefins}

An internal olefin is less reactive compared to a terminal olefin due to steric hindrance. To circumvent this problem, various conditions have been developed. $\mathrm{P}(\mathrm{t}-\mathrm{Bu})_{3}$ is an electron-rich and highly bulky phosphine ligand, and effective for various crosscouplings[8]. In 2001, Fu reported a $\mathrm{M}-\mathrm{H}$ reaction of internal olefins using a $\mathrm{Pd} / \mathrm{P}(\mathrm{t}-\mathrm{Bu})_{3}$ catalyst system (Scheme 4)[9]. $\mathrm{Ar}-\mathrm{Br}$ can be employed under the conditions even at room temperature. When $(E)$-internal olefins 4.1, acrylates, are used products are formed with highly E-selectivity 4.2 in good yields. The $\mathrm{Pd} / \mathrm{P}(\mathrm{t}-\mathrm{Bu})_{3}$ catalyst system is also effective for the reaction of $\mathrm{Ar}-\mathrm{Cl}$ at $120^{\circ} \mathrm{C}$, in which $(E)-4.2$ is predominantly generated.
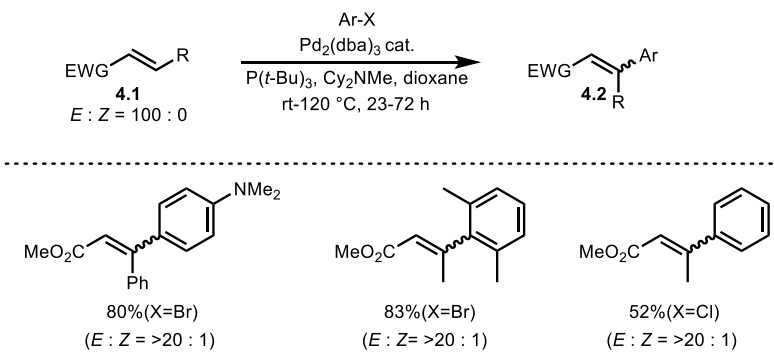

Scheme 4. $P d / P(t-B u)_{3}$ catalyst system

In aqueous media, a p-hydroxyacetophenone oxime-derived palladacycle catalyst is effective for the $\mathrm{M}-\mathrm{H}$ reaction with internal olefins 5.1 (Scheme 5) [10]. $\beta$, $\beta$-diaryl products 5.2 are obtained in good yields under the conditions. Despite the use of $(E)$-substrates 5.1, selectivities are not perfect. $\pi$-conjugated products $\mathbf{5 . 2}$ may undergo isomerization from $(E)$ to $(Z)$ at 120 ${ }^{\circ} \mathrm{C}$ in the presence of the palladacycle.
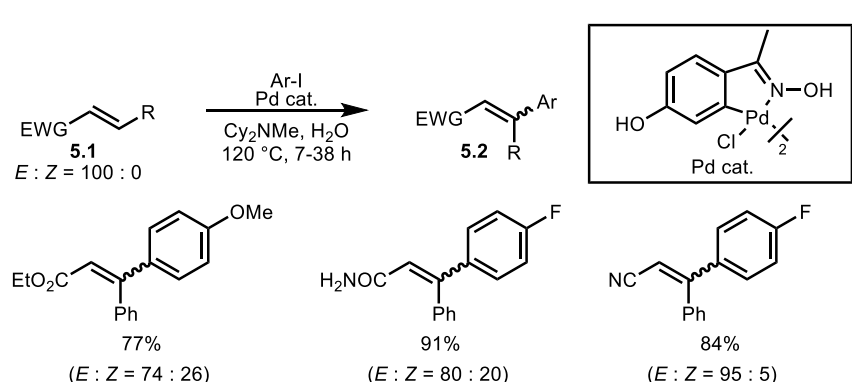

Scheme 5. $p$-Hydroxyacetophenone oxime-derived palladacycle catalyst system on water

An isoxazoline ligand with a ferrocene backbone enables $\mathrm{Pd}$ catalyzed $\mathrm{M}-\mathrm{H}$ reactions with internal olefins 6.1 (Scheme 6) [11]. $\beta, \beta$-diaryl products 6.2 are obtained in good yields and high selectivities. In this case, no (Z)-products 6.2 were detected, in contrast to the reaction shown in Scheme 5 . The reason for the lack of isomerization is not explained in the paper, but the 
catalyst bearing the isoxazoline ligand might not be an effective catalyst for isomerization of $\mathbf{6 . 2}$.

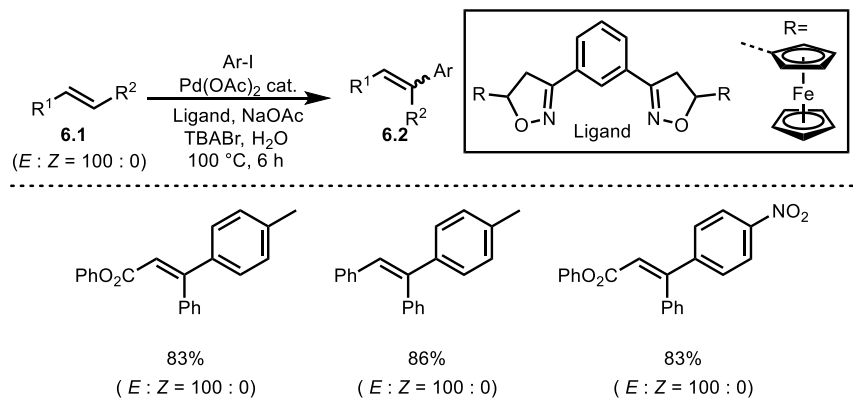

Scheme 6. Pd/isoxazoline ligand with ferrocene backbone catalyst system

Boronated aryl iodides can be coupled with internal olefins 7.1 to give boronated products 7.2 using a $\mathrm{Pd} / 1,3$-diketone ligand catalyst system (Scheme 7)[12]. Generally, $\mathrm{ArBF}_{3} \mathrm{~K}$ is easily coupled with Ar-I, but boronated aryl iodides do not undergo Suzuki-Miyaura coupling in the presence of internal olefins 7.1, from which $\mathrm{M}-\mathrm{H}$ products $\mathbf{7 . 2}$ are obtained in good yields and with perfect $(E)$-selectivity. In this case, $\beta$, $\beta$-diaryl products $\mathbf{7 . 2}$ are not isomerized under the conditions.

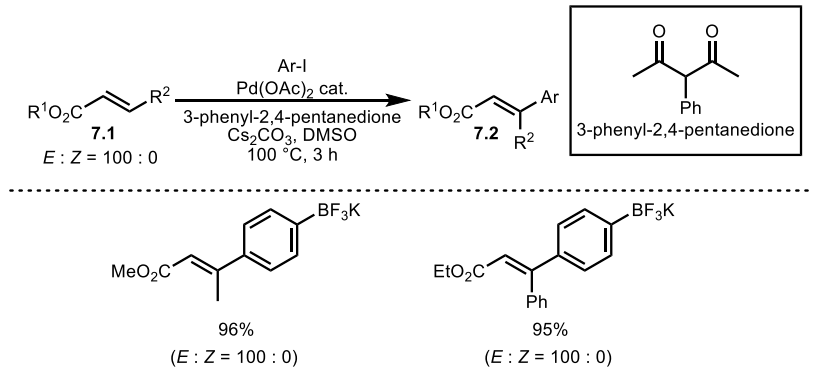

Scheme 7. The reaction with a diketone ligand

Fu's conditions (Scheme 4) enabled the $\mathrm{M}-\mathrm{H}$ reaction of internal olefins and simple $\mathrm{Ar}-\mathrm{Br}$ at room temperature in the presence of $\mathrm{P}(t-\mathrm{Bu})_{3}$ as a ligand for a $\mathrm{Pd}$ catalyst. The reactions with internal olefins generally require higher reaction temperature over $100^{\circ} \mathrm{C}$ due to the low reactivity of internal olefins. When the $\mathrm{M}-\mathrm{H}$ reaction of internal olefin $\mathbf{8 . 1}$ and $\mathrm{Ar}-\mathrm{Br}$ possessing a heterocycle or a phenol moiety was carried out in the presence of a $\mathrm{Pd}$ catalyst $\left[\mathrm{Pd}\left(\mathrm{tBu}_{3} \mathrm{P}\right)_{2}\right.$ or $\mathrm{PdCl}_{2}(\mathrm{DtBPF})$ (DtBPF=1,1'-bis(ditertbutylphosphino)ferrocene)] is carried out at $80{ }^{\circ} \mathrm{C}$, products $\mathbf{8 . 2}$ are obtained in moderate yields due to catalyst poisoning but selectivities are perfect (Scheme 8) [13]. The $\mathrm{M}-\mathrm{H}$ reaction of internal olefin 9.1 and electron-deficient Ar$\mathrm{Cl}$ under $\mathrm{Pd} / \mathrm{DavePhos}$ conditions also results in a moderate yield of 9.2 (Scheme 9) [14]. These results clearly illustrate the low reactivity of internal olefins for the $\mathrm{M}-\mathrm{H}$ reaction. High reaction temperature (over $100 \stackrel{\circ}{\circ}$ ) or special ligands must be employed to achieve the $\mathrm{M}-\mathrm{H}$ reaction of internal olefins with good yields.

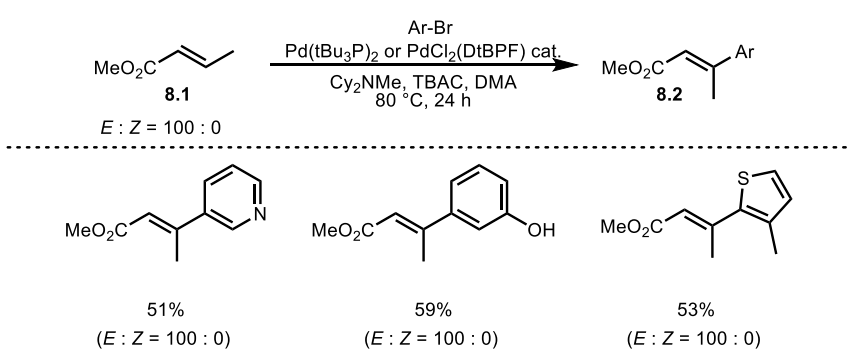

Scheme 8. The reaction with a heterocyclic substrate

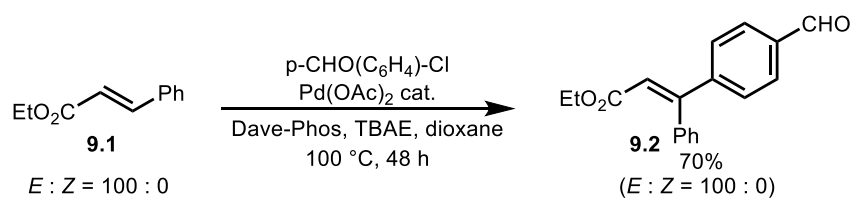

Scheme 9. The reaction in the presence of Buchwald's ligand

Simple $\mathrm{Pd}(\mathrm{OAc})_{2}$ can be used in combination with $\mathrm{AgOAc}$ for $\mathrm{M}-\mathrm{H}$ reactions with internal olefins 10.1 in $\mathrm{AcOH}$ at $110^{\circ} \mathrm{C}$ (Scheme 10)[15]. Yields of products $\mathbf{1 0 . 2}$ are in a range between 92 to $98 \%$ but selectivities are moderate. Ligands, such as trialkylphosphine, are effective for increasing the catalyst reactivity in the $\mathrm{M}-\mathrm{H}$ reaction with internal olefins, but the reaction of $\mathbf{1 0 . 1}$ and both electron-deficient and -rich Ar-I smoothly occurs without any ligands in this case. This highly reactive catalyst system can be explained by the generation of cationic $\mathrm{Pd}$ species from the reaction of $\mathrm{Ar}-\mathrm{Pd}-\mathrm{I}$ and a silver salt in $\mathrm{AcOH}$. The reason for isomerization of the products is not clear but the activated cationic catalyst species might be responsible.

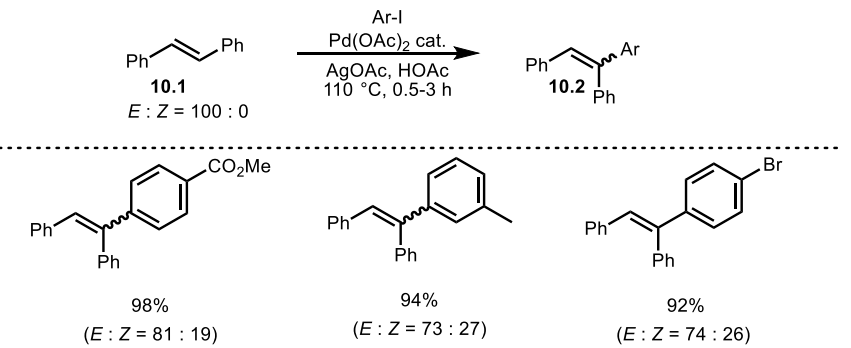

Scheme 10. The reaction in $\mathrm{AcOH}$

Pd nano particles (NPs) are an attractive catalyst for transition metal-catalyzed cross-coupling reactions [16]. The reactivities 
sometimes depend on the size of each particle but the catalytic activitiy does not exceed that of homogeneous catalysts in most cases. Nacci's group reported the $\mathrm{M}-\mathrm{H}$ reaction of internal olefins 11.1 and $\mathrm{ArCl}$ in the presence of Pd NPs (Scheme 11) [17]. A tetrabutylammonium salt is a good stabilizer for small $\mathrm{Pd}$ NPs and good yields (80 to $94 \%$ ) of $\mathbf{1 1 . 2}$ are obtained, but selectivities are not perfect probably due to the high activity of the catalyst. This reaction is a heterogeneous system but the catalyst cannot easily be recycled because of the particle size. Pd NPs can be embedded onto resin beads. These resin beads containing Pd NPs (SS-Pd) efficiently catalyze the $\mathrm{M}-\mathrm{H}$ reaction with internal olefins $\mathbf{1 2 . 1}$ and the catalyst can be recycled after the reaction in this case (Scheme 12) [18]. The reactions smoothly occur with methyl substituted internal olefins $\mathbf{1 2 . 1}$ but selectivity is not perfect in the case of $p$-nitrophenyl substituted 12.1.

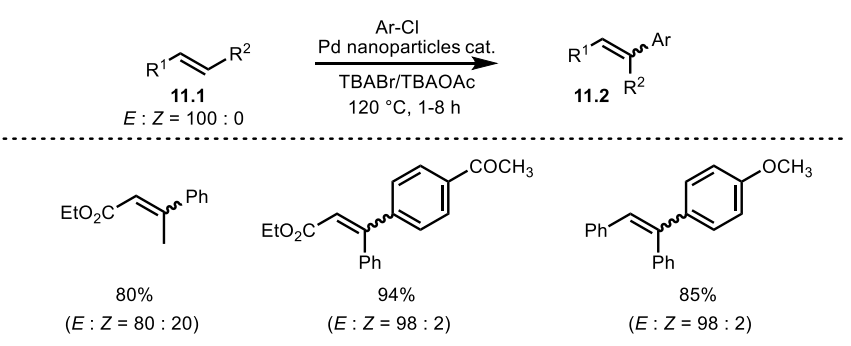

Scheme 11. Pd NPs as a catalyst

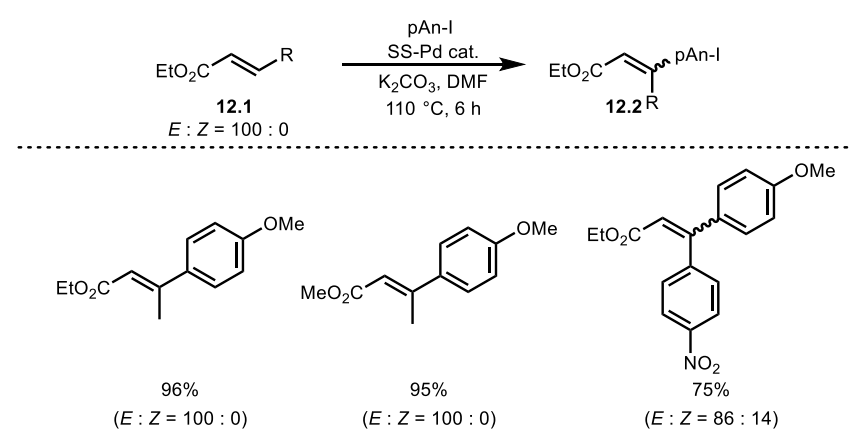

Scheme 12. SS-Pd as a catalyst

$\beta$-Aryl or alkyl substituted acrylamides (13.1 and 14.1) are also good substrates for the $\mathrm{M}-\mathrm{H}$ reaction. Interestingly, reactivities and stereoselectivities of $\beta$-aryl or alkyl substituted acrylamides depend on the structure of the carboxamide moiety. For example, $N, N$-dimethyl $\beta$-aryl acrylamides $13.1(\mathrm{R}=\mathrm{Me})$ give the $\mathrm{M}-\mathrm{H}$ product $\mathbf{1 3 . 2}$ with higher selectivity than the corresponding

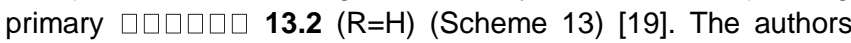
explain that the different selectivities can be attributed to the coordination of the caboxamide group to $\mathrm{Pd}$. This chelation effect is discussed below. On the other hand, the reaction of vinylic Weinreb amides $\mathbf{1 4 . 1}$ gives higher selectivities (Scheme
14) [20]. A Pd catalyst possessing an NHC ligand efficiently catalyzes the $\mathrm{M}-\mathrm{H}$ reaction of $\mathbf{1 4 . 1}$ and Arl to produce the corresponding product $\mathbf{1 4 . 2}$ in good yield and with perfect selectivity. These perfect selectivities might be attributed to the chelation effect of the palladium catalyst to the Weinreb amide but the reason is not clear.

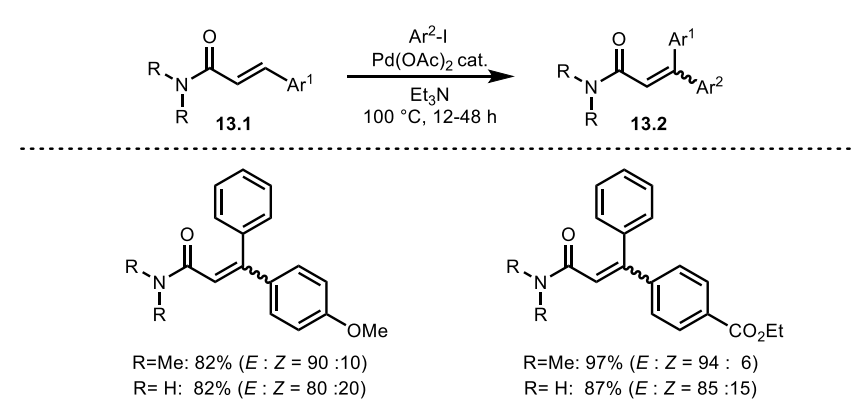

Scheme 13. The reaction with acrylamide

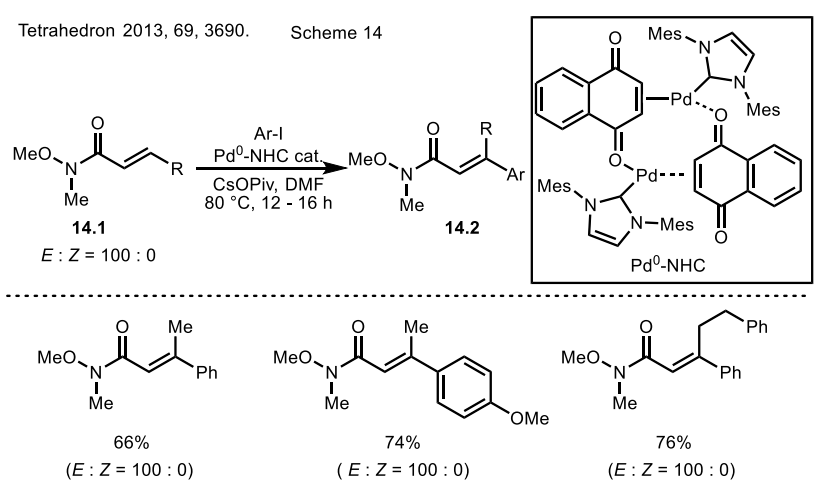

Scheme 14. The reaction with a NHC ligand

The reactivities of styrene, acrylonitrile, and acrylate possessing a vinylic ether moiety $(\mathbf{1 5 . 1}, 15.2$ and 15.3) were examined in the $\mathrm{M}-\mathrm{H}$ reaction with a $\mathrm{Pd} /$ tetraphosphine (Tedicyp) catalyst system (Scheme 15) [21]. The reaction of $15.1(E: Z=98: 2)$ resulted in the product 15.4 in $58 \%$ yield $(E: Z=$ $35: 65)$. Similarly, lower selectivities are observed in the reaction of 15.2 and 15.3. The electronic properties of the ether functional group might affect the diastereoselectivities in these reactions.
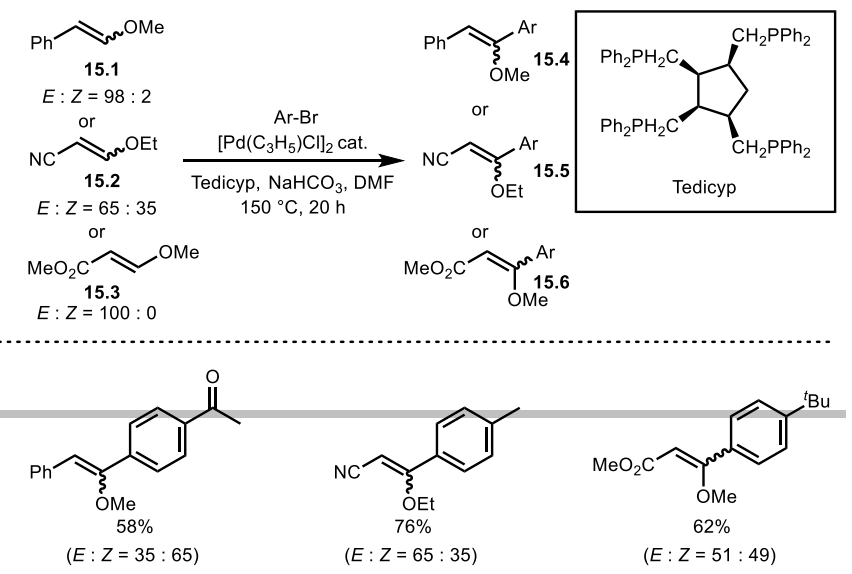
Scheme 15. The reaction with Tedicyp ligand

A Pd/carbethoxyurea (CEPU) catalyst system is effective for carrying out the $\mathrm{M}-\mathrm{H}$ reaction with internal olefins. In this system, $\beta$-substituted- $\alpha, \beta$-unsaturated aldehydes and esters (16.1) can be applied to the reaction (Scheme 16) [22]. The chemical yields of $\mathbf{1 6 . 2}$ are good but the selectivities are very low. Moreover, only electron-rich aryl iodides show reactivity for internal olefins. The conditions including solvent, base, and reaction temperature are slightly different from other reports of $\mathrm{M}-\mathrm{H}$ reactions with internal olefins, but selectivities cannot be controlled under these conditions. The Pd/CEPU catalyst system may catalyze isomerization of the products $\mathbf{1 6 . 2}$.

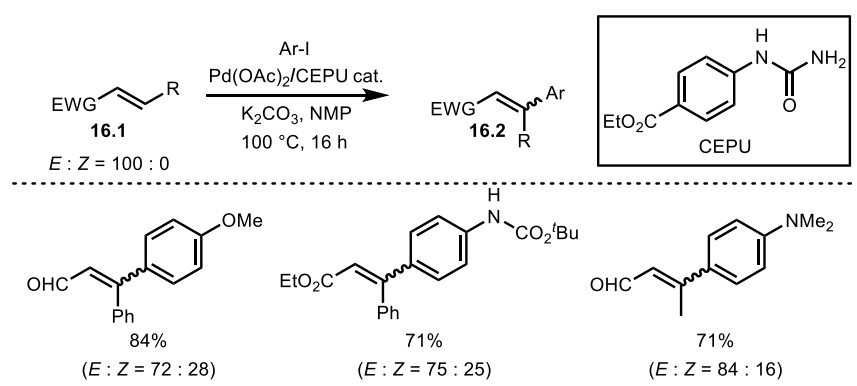

Scheme 16. The reaction with CEPU ligand

Unprotected functional groups including amines, alcohols, phenols, thiols, and carboxylic acids sometimes affect the catalyst activities for transition-metal catalyzed reactions. An ionic liquid as a reaction solvent enables $\mathrm{M}-\mathrm{H}$ reaction with $\beta$ substituted- $\alpha, \beta$-unsaturated carboxylic acids $\mathbf{1 7 . 1}$ as the internal olefin (Scheme 17) [23]. The reaction of $\mathbf{1 7 . 1}$ and aryl iodide in the presence of the $\mathrm{Pd}$ catalyst gives the corresponding coupling product $\mathbf{1 7 . 2}$ at $120{ }^{\circ} \mathrm{C}$. The chemical yields of $\mathbf{1 7 . 2}$ are moderate but selectivities are good.

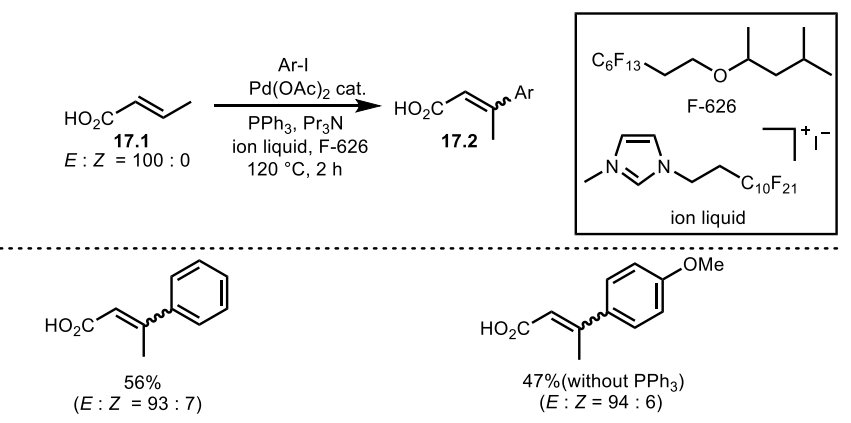

Scheme 17. The reaction in ionic liquid
Sulfur compounds, such as $\beta$-substituted- $\alpha, \beta$-unsaturated sulfoxides also react with aryl halides in the presence of a $\mathrm{Pd}$ catalyst to give $\mathrm{M}-\mathrm{H}$ products. For example, $\beta$-substituted- $\alpha, \beta$ unsaturated sulfoxides $\mathbf{1 8 . 1}$ possessing $N, N$-dimethylaniline as a directing group react smoothly with $\mathrm{Arl}$ to produce the corresponding products $\mathbf{1 8 . 2}$ in moderate yields with good selectivities (Scheme 18) [24]. The amine directing group is necessary to increase the reactivity of the sulfoxide substrate in the presence of the $\mathrm{Pd} / \mathrm{dppf}$ catalyst. The $\mathrm{M}-\mathrm{H}$ reaction of $\alpha, \beta-$ substituted- $\alpha, \beta$-unsaturated sulfoxides without a directing group requires Fu's conditions $\left(\mathrm{Pd} / \mathrm{P}(\mathrm{t}-\mathrm{Bu})_{3}\right)$. For example, the reactions of 19.1 and $\mathrm{ArBr}$ smoothly produce $\mathrm{M}-\mathrm{H}$ products 19.2 in the presence of $\mathrm{P}(\mathrm{t}-\mathrm{Bu})_{3}$ but the reaction even with a terminal olefin does not occur with a $\mathrm{Pd} / \mathrm{PPh}_{3}$ catalyst system (Scheme 19) [25].

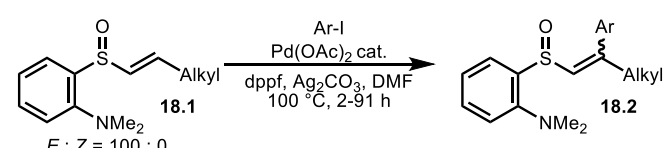

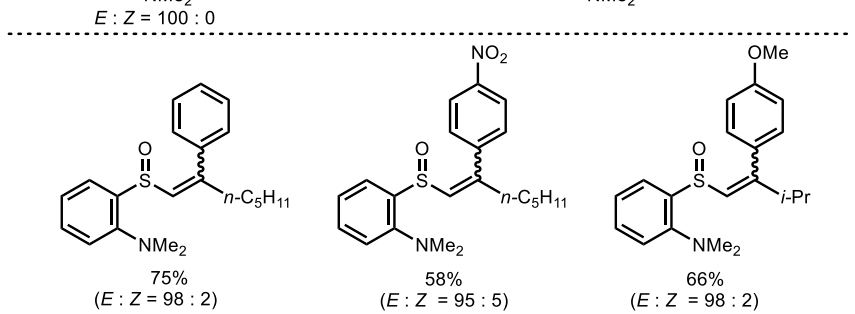

Scheme 18. The reactivity of sulfoxide substrate possessing dimethylamino group

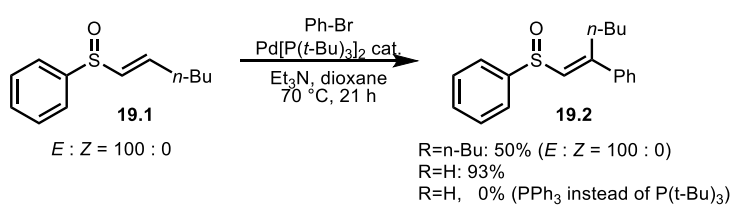

Scheme 19. The reactivity of sulfoxide substrate

Vinylic boron reagents are one of the most attractive reactants for the $\mathrm{M}-\mathrm{H}$ reaction because the corresponding boronated products can be used for further transformations via SuzukiMiyaura coupling. The reactions of vinylic MIDA boronates 20.1 with Arl under a $\mathrm{Pd}(\mathrm{OAc})_{2} / \mathrm{AgOAc}$ catalyst system produces $\mathbf{2 0 . 2}$ in good yields with moderate to good selectivities (Scheme 20) [26]. The reaction is carried out at $80^{\circ} \mathrm{C}$ without special ligands, such as trialkylphosphines, but the results are good.

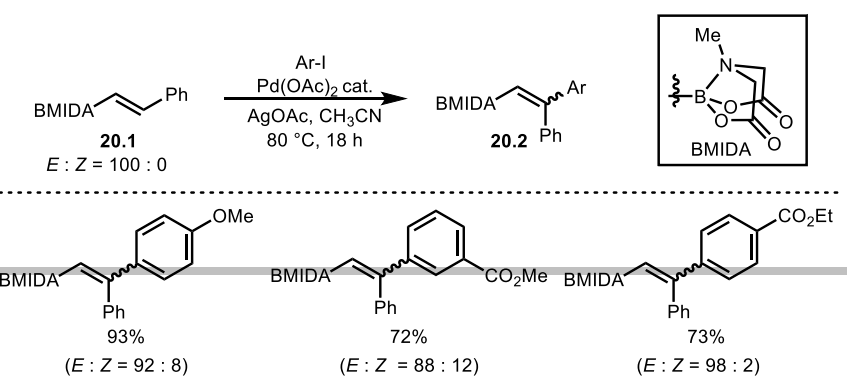


Scheme 20. The reaction with aryl-BMIDA

Various $\beta$-substituted- $\alpha, \beta$-unsaturated compounds can be employed for the $\mathrm{M}-\mathrm{H}$ reaction, and results are mostly good as outlined above. On the other hand, aryl electrophiles other than aryl halides can be also applicable to the reaction under $\mathrm{Pd}$ catalyst conditions. Arylsulfonyl hydrazides $\left(\mathrm{ArSO}_{2} \mathrm{NHNH}_{2}\right)$ are good reagents for the $\mathrm{M}-\mathrm{H}$ reaction in the presence of a $\mathrm{Pd}$ catalyst (Scheme 21) [27]. In this reaction, an active arylpalladium acetate is generated after the releasing of $\mathrm{SO}_{2}$ and $\mathrm{N}_{2}$ from in situ generated $\mathrm{ArSO}_{2} \mathrm{NHNH}-\mathrm{Pd}-\mathrm{OAc}$, which is generated from the reaction of $\mathrm{ArSO}_{2} \mathrm{NHNH}_{2}$ and $\mathrm{Pd}(\mathrm{OAc})_{2}$ under oxygen atmosphere at $70{ }^{\circ} \mathrm{C}$. The resulting arylpalladium acetate reacts with $\mathbf{2 1 . 1}$ to produce $\mathbf{2 1 . 2}$ in moderate yields and with perfect selectivities. Aryldiazonium tetrafluoroborates are also very effective electrophiles for the $\mathrm{M}-\mathrm{H}$ reaction (Scheme 22 and 23) [28,29]. In this reaction, a mono-cationic arylpalladium species is generated from the reaction of $\mathrm{Pd}^{0}$ and an aryldiazonium tetrafluoroborate. This cationic palladium is more reactive towards an olefin compared than a neutral one [30]. Therefore, aryldiazonium tetrafluoroborates are considered to be the best aryl electrophile in the $\mathrm{M}-\mathrm{H}$ reaction with unreactive internal olefins. For example, electron-rich aryldiazonium salts undergo $\mathrm{M}-\mathrm{H}$ reaction of internal olefins (22.1) under reflux conditions in $\mathrm{MeOH}$ (Scheme 22). But electron-deficient ones react with $\mathbf{2 2 . 1}$ at room temperature without special ligands, such as $\mathrm{P}(t-\mathrm{Bu})_{3}$. On the other hand, the $\mathrm{M}-\mathrm{H}$ reaction of aryldiazonium tetrafluoroborates and $\mathbf{2 3 . 1}$ in the presence of $\mathrm{NaOAc}$ as a base and $\mathrm{MeOH} / \mathrm{MeCN}$ as a solvent occurs at $70{ }^{\circ} \mathrm{C}$ (Scheme 23). Both of the reactions shown in Scheme 22 and 23 produce the corresponding products $(22.2$ and 22.3) in good yields with selectivties ranging from moderate to good.

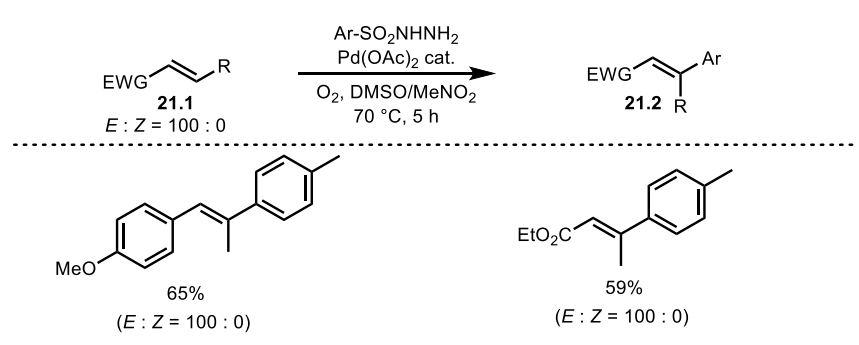

Scheme 21. The reaction with $\mathrm{ArSO}_{2} \mathrm{NHNH}_{2}$
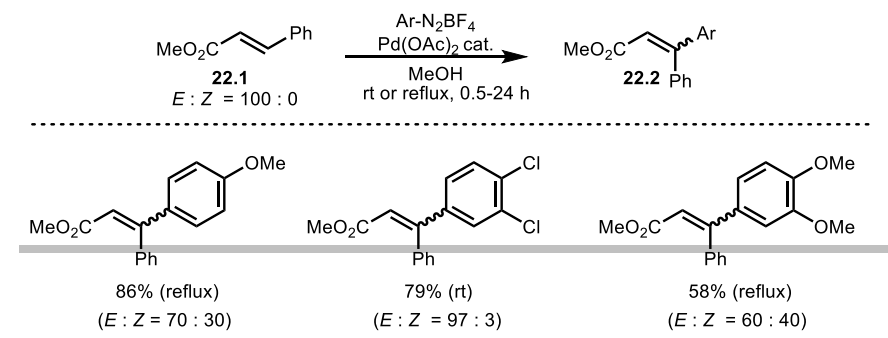

Scheme 22. The reaction with $\mathrm{ArN}_{2} \mathrm{BF}_{4}$

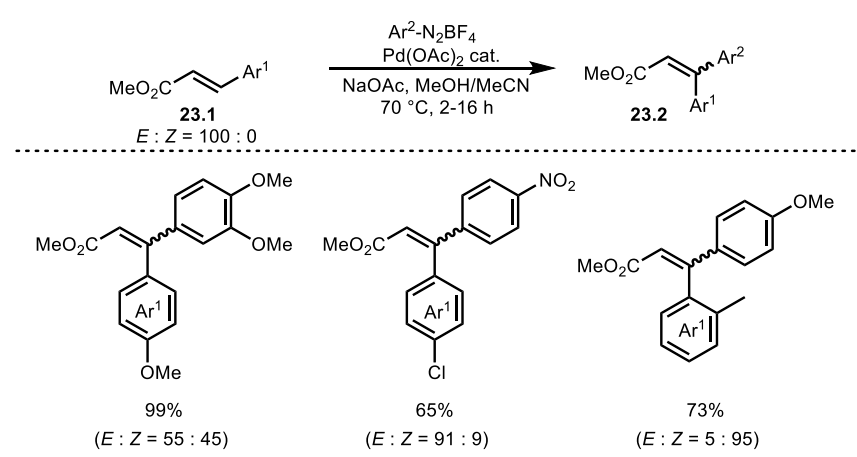

Scheme 23. The reaction with $\mathrm{ArN}_{2} \mathrm{BF}_{4}$ in the presence of $\mathrm{NaOAc}$

\section{Chelation-controlled $\mathrm{M}-\mathrm{H}$ reaction}

Tuning of reaction conditions can be very effective for carrying out $\mathrm{M}-\mathrm{H}$ reactions with poorly reactive internal olefins. Another methodology to overcome poor reactivity of internal olefins is to use a directing group, which provides a chelation effect to increase the coordination ability of $\mathrm{Ar}-\mathrm{PdX}$ towards a C-C double bond (Figure 1). After the coordination of Ar-PdX to the alkene, carbopalladation smoothly occurs at the $\beta$-position with respect to the directing group.

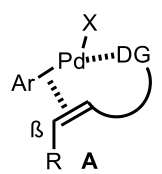

Enhancing reactivity of internal olefin $100 \%$ ß-selective

Figure 1. Effect of a directing group

Pyridine and pyrimidine are good directing groups for $\mathrm{M}-\mathrm{H}$ reactions with internal olefins. Itami and Yoshida's group reported the one-pot reaction of pyridyl(vinyl)silanes or pyrimidyl(vinyl)sulfides and two different Ar-I to produce trisubstituted olefins in the presence of a Pd catalyst (Scheme 24 and 25)[31,32]. The first reaction of 24.1 with $\mathrm{Ar}^{1}-1$ produces the trans $\mathrm{M}-\mathrm{H}$ product. The following arylation with $\mathrm{Ar}^{2}-\mathrm{I}$ produces 24.2 in good yields with perfect $E$-selectivity (Scheme 24). Similarly, pyrimidyl(vinyl)sulfides react with two different aryl iodides (Shceme 25). The results of one-pot double $\mathrm{M}-\mathrm{H}$ 
reactions are perfectly stereo- and regioselective with the aid of the directing group. Both pyridylsilyl groups and pyrimidylsulfide groups can be utilized for further cross-couplings with Grignard reagents or aryl halides in the presence of a $\mathrm{Pd}$ catalyst.

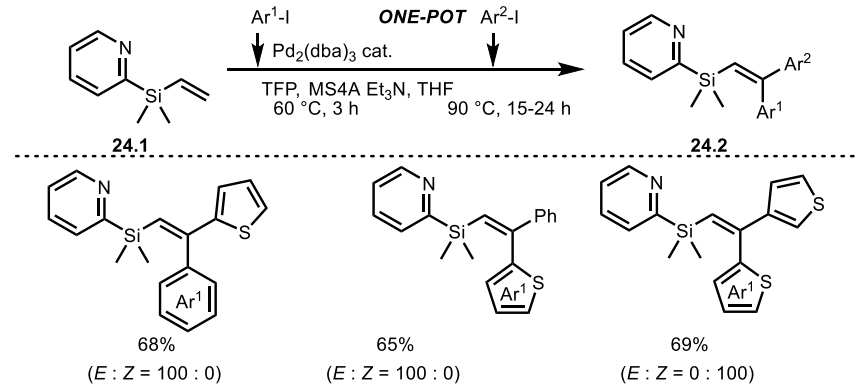

Scheme 24. Substrate possessing pyridyl group

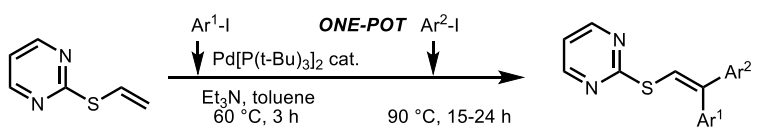

25.1 25.2<smiles>COc1ccc(C(=CSc2ncccn2)c2ccc(OC)cc2)cc1</smiles>

Scheme 25. Substrate possessing pyrimidyl group

The $\mathrm{M}-\mathrm{H}$ reaction of internal olefins typically gives $(E)$ selectivity. To obtain the (Z)-product from the reaction of an internal olefin and an aryl halide, a vinylic $\mathrm{C}-\mathrm{H}$ functionalization process is one of the most promising approaches. The reaction of trans 2-vinylic pyridine $\mathbf{2 6 . 1}$ and an aryl bromide in the presence of a $\mathrm{Ru}$ catalyst leads to a vinylic $\mathrm{C}-\mathrm{H}$ arylation reaction to produce a (Z)-arylated product $\mathbf{2 6 . 2}$ in good yield and with perfect selectivity (Scheme 26)[33]. The reaction of $(E)$ stilbene and $\mathrm{ArBr}$ results in no product, which indicates the importance of the pyridyl group as a directing group. A key intermediate of this reaction is a nitrogen-atom coordinated ruthenacycle via ruthenation of the vinylic hydrogen of 26.1. This $\mathrm{C}-\mathrm{H}$ functionalization methodology gives complementary $(E, Z)$ selectivity to the $\mathrm{M}-\mathrm{H}$ reaction.
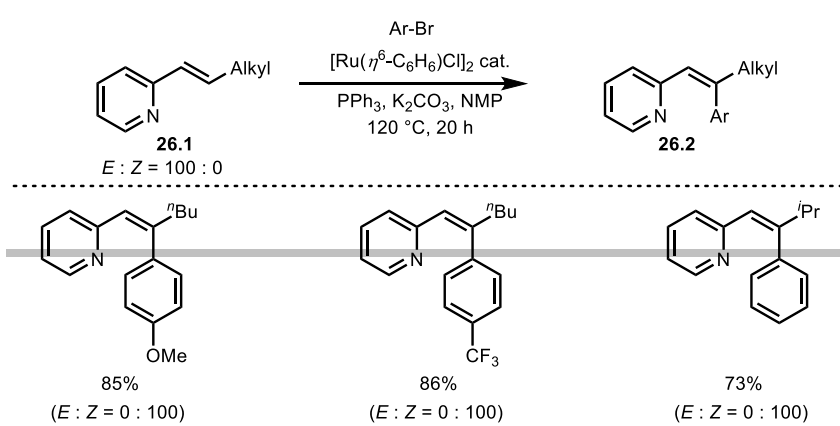

Scheme 26. 2-Pyridyl directing group for Ru-catalyzed reaction

In the $\mathrm{M}-\mathrm{H}$ reactions, $E$ substrates are employed to obtain a single diastereomer. When the reaction is carried out with $E, Z$ mixed substrates 27.1, $(E, Z)$-mixed products are obtained, in which $(E)$ and $(Z)$ ratios of substrates are matched with those of the starting material 27.1 (Scheme 27)[34]. The reaction is not convergent, which indicates that the formation of a $\mathrm{C}-\mathrm{C}$ double bond via $\beta-\mathrm{H}$ elimination is quite predictable.

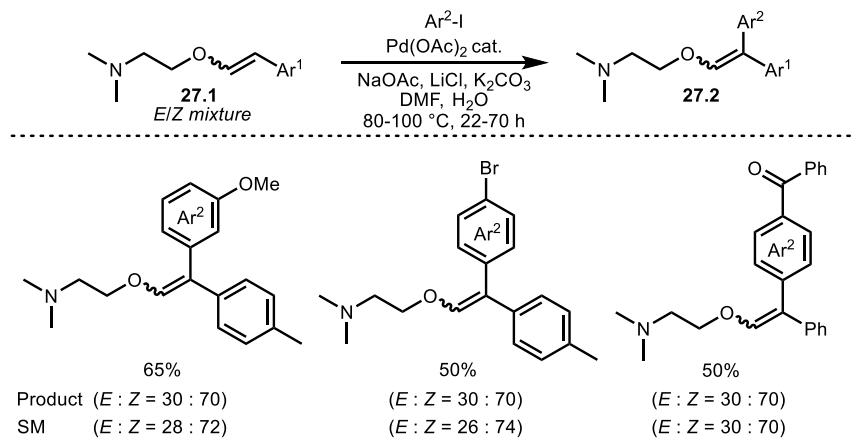

Scheme 27. Substrate possessing dimethylaminoethyl group

As was shown in Scheme 18 and 19, the $N, N$-dimethylamino group was effective as a directing group in the reaction of $\beta$ substituted- $\alpha, \beta$-unsaturated sulfoxides 18.1 and aryl halides. The $\mathrm{M}-\mathrm{H}$ reaction of $\beta$-substituted- $\alpha, \beta$-unsaturated sulfones $\mathbf{2 8 . 1}$ possessing a $\mathrm{N}, \mathrm{N}$-dimethylaniline group gives the corresponding $(E)$-products $\mathbf{2 8 . 2}$ in good yields with perfect selectivities (Scheme 28)[35]. An $\mathrm{N}$-coordinated palladacycle is generated after arylpalladation to $\mathbf{2 8 . 1}$ to produce $(E)-\mathbf{2 8 . 2}$ exclusively. The presence of a silver salt is important to generate a cationic palladium species, which undergoes facile coordination to the olefin and amino directing group.
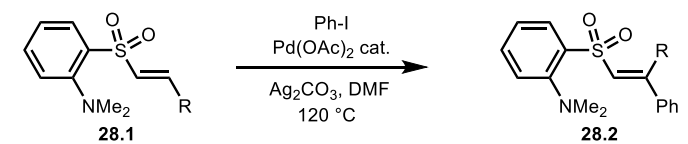

$E: Z=100: 0$ $E: Z \stackrel{28.2}{=} 100: 0$
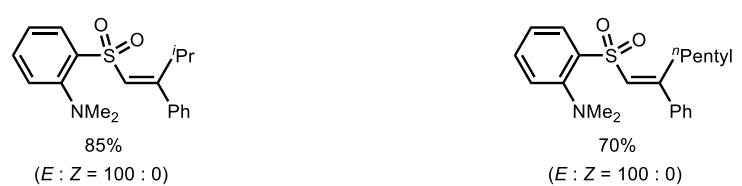

$(E: Z=100: 0)$

Scheme 28. Substrates possessing a dimethylaniline group 


\section{Heck reaction with arylboron or -silicon reagents}

Aryl halides are good coupling partners for the $\mathrm{M}-\mathrm{H}$ reaction, but arylboron or -silicon reagents are also applicable to the reaction in the presence of a appropriate oxidant. The reaction of an arylboron or -silicon reagent and $\mathrm{PdX}_{2}$ produces $\mathrm{Ar}-\mathrm{PdX}$ via a transmetallation process. After carbopalladation followed by $\beta-\mathrm{H}$ elimination, the corresponding Heck product and $\mathrm{Pd}^{0}$ (after reductive elimination of $\mathrm{HPdX}$ ) are generated. An oxidant is required to regenerate a $\mathrm{Pd}^{\text {ll }}$ species to start a $2^{\text {nd }}$ catalytic cycle. This type of the reaction is referred to as an oxidative Heck reaction. Heck originally employed the reaction involving a transmetallation process with arylmercury, -tin, and other species [36] and generally employed terminal olefins to obtain trans products in good yields. The reaction is also unsuitable for internal olefins like the original $\mathrm{M}-\mathrm{H}$ reaction. Therefore, most of the reactions shown in this section require high temperatures to obtain good yields of the $\mathrm{M}-\mathrm{H}$ products. To increase the reactivity of less reactive internal olefins, a directing group is effective, as was shown in section 3. For example, amidomethyl substituted acrylates 29.1 react smoothly with arylboronic acids at room temperature in the presence of a $\mathrm{Pd}$ catalyst and TEMPO (2,2,6,6-tetramethylpiperidine 1-oxyl) as an oxidant (Scheme 29)[37]. In this reaction, only $(E)$-products are obtained from $(E)-29.1$. This mild reaction is attributed to the effect of the aminomethyl directing group.

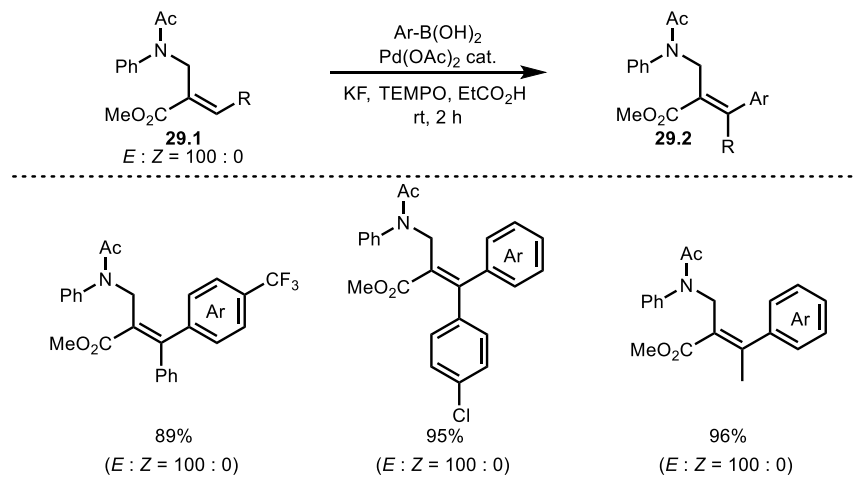

Scheme 29. The reaction in the presence of tempo as an oxidant

The nature of the arylboronic acid and olefin structure (having a directing group or not) influences the reactivity and the product selectivity. Tuning the reaction conditions also affects the reaction. Studer's group reported that 4-hydroxylated TEMPO as an oxidant and a carboxylic acid as a solvent are most effective to carry out the oxidative Heck reaction at room temperature (Scheme 30)[38]. This condition is very effective to obtain the product $\mathbf{3 0 . 2}$ from styrene derivatives $\mathbf{3 0 . 1}$ in good yields and selectivities, but the reason for this high reactivity is unclear.

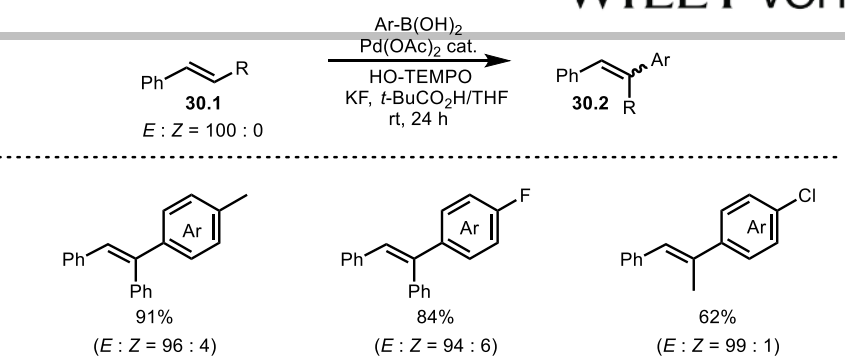

Scheme 30. The effect of modified tempo as an oxidant

Copper is employed as an oxidant for the reaction of acrylate dervatives 31.1 (Scheme 31)[39]. The reactions of $\mathbf{3 1 . 1}$ and arylboronic acids in the presence of a $\mathrm{Pd}$ catalyst and excess $\mathrm{Cu}(\mathrm{OAc})_{2}$ give the corresponding Heck products $\mathbf{3 1 . 2}$ in moderate yields with perfect $(E)$-selectivities. In the case of substituted enamides 32.1, $\mathrm{Cu}(\mathrm{OAc})_{2}$ is also effective as a catalytic oxidant in combination with oxygen (Scheme 32)[40]. This enamide group in $\mathbf{3 2 . 1}$ could act as a directing group but increased reactivity of the substrate is not observed. The yields and selectivities of $\mathbf{3 2 . 1}$ are high under the conditions. In both cases, copper did not affect the diastereoselectivities.

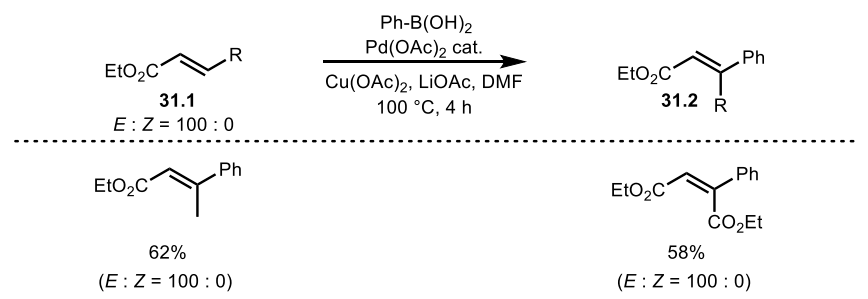

Scheme 31. The reaction in the presence of $\mathrm{Cu}$ as an oxidant

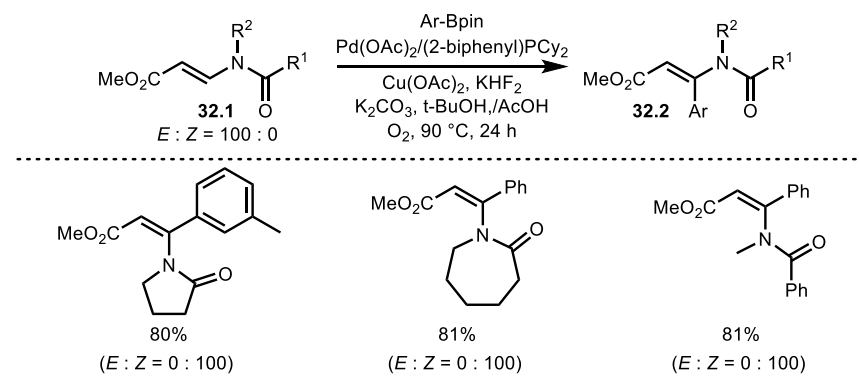

Scheme 32. The reaction with enamide

Strong acid as a solvent is effective for carrying out an oxidative Heck reaction without any oxidant. When arylboronic acids react with 33.1 in $\mathrm{CF}_{3} \mathrm{CO}_{2} \mathrm{H}$ (TFA), the corresponding Heck products $\mathbf{3 3 . 2}$ are produced in a good yields with perfect $(E)$ selectivities (Scheme 33)[41]. To complete the catalytic cycle, an oxidant is required to re-generate a $\mathrm{Pd}^{\text {Il }}$ species, because the $\mathrm{H}$ $\mathrm{Pd}^{\mathrm{I}}-\mathrm{X}$ species after $\beta-\mathrm{H}$ elimination readily converts into $\mathrm{Pd}^{0}$ and $H X$. The resulting $\mathrm{Pd}^{0}$ species needs to be oxidized by an oxidant to generate a Pd" species, but the reaction of TFA and $\mathrm{H}-\mathrm{Pd}$ "-X can potentially generate a X-Pd"-X species directly [42], which can undergo transmetallation with the arylboronic acid . 


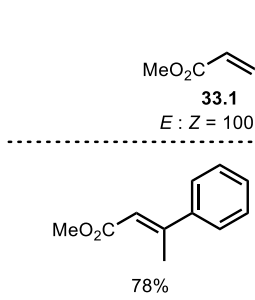

$(E: Z=100: 0)$

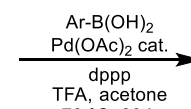
\begin{tabular}{l}
$70^{\circ} \mathrm{C}, 20 \mathrm{~h}$ \\
\hline
\end{tabular}
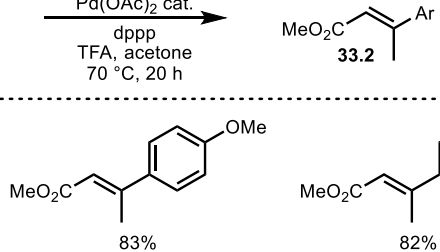

$(E: Z=100: 0)$

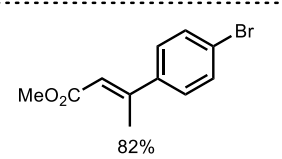

$(E: Z=100: 0)$

Scheme 33. The reaction in strong acid

Organosilicon reagents are also good aryl donors for the oxidative Heck reaction. The reaction of arylsilanols and $\mathbf{3 4 . 1}$ in the presence of a Pd catalyst and a copper oxidant gave Heck products 34.2 in moderate to good yields (Scheme 34)[43]. In the case of the reaction with fumarate, the product selectivity is perfect, but crotonate gives $(E)$ and $(Z)$-mixtures of 34.2. The oxidative Heck reactions with arylboron and -tin reagents sometimes suffer from homocoupling side reactions to give $\mathrm{Ar}_{2}$. A key benefit of the arylsilicon reagents is that they do not form ahomocoupling product in the reaction.

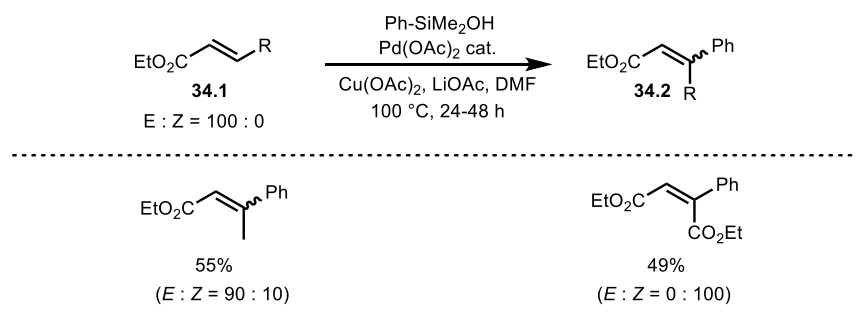

Scheme 34. Arylsilanol as an aryl donor

\section{Alkylative $\mathrm{M}-\mathrm{H}$ reaction}

It is well known that alkylation is one of the most challenging reactions in transition metal-catalyzed chemistry. Alkylative $\mathrm{M}-\mathrm{H}$ reactions [1a] [44] have been studied, but it is very difficult to obtain the corresponding products with good yields because of the strong tendency of the alkylmetal intermediate to undergo " $\beta$ hydride elimination reaction" during the reactions. Although many chemists have devoted their energy to this field, existing methodologies almost always employ a combination of terminal olefins and alkyl halides. Only a few examples of reactions with internal olefins have been described. Moreover, the reaction mechanism is sometimes different from the original $\mathrm{M}-\mathrm{H}$ reaction, as it involves alkyl radical generation followed by the addition to the olefin then hydrogen elimination. The alkylative $\mathrm{M}-\mathrm{H}$ reaction can therefore be distinguished from the original $\mathrm{M}-\mathrm{H}$ reaction[1a] but the mechanistic details of alkylative $\mathrm{M}-\mathrm{H}$ reactions will not be discussed in this review.

The reaction of a secondary alkyl iodide (cyclohexyl iodide) and $\beta$-methyl styrene (35.1) gives $(E)$-product 35.2 in $17 \%$ yield under irradiation conditions (Scheme 35) [45]. In this reaction, no $\mathrm{Pd}$ catalyst is needed, and a free radical mechanism is operative. When terminal olefins, such as styrene derivatives, are employed, good yields of the products are obtained. On the other hand, $\mathrm{Pd}$ catalyst conditions are used instead of irradiation

in the reaction of trans crotonates $\mathbf{3 6 . 1}$ with alkyl iodides. The corresponding products $\mathbf{3 6 . 2}$ are obtained in good yield, but the selectivities are low (Scheme 36) [46]. This reaction is also likely to proceed through a radical pathway. Unlike arylative $\mathrm{M}-\mathrm{H}$ reactions, selectivities cannot readily be controlled in these processes.

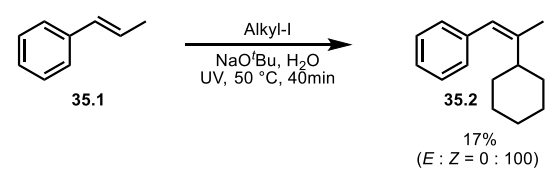

Scheme 35. Alkylation uder UV irradiation

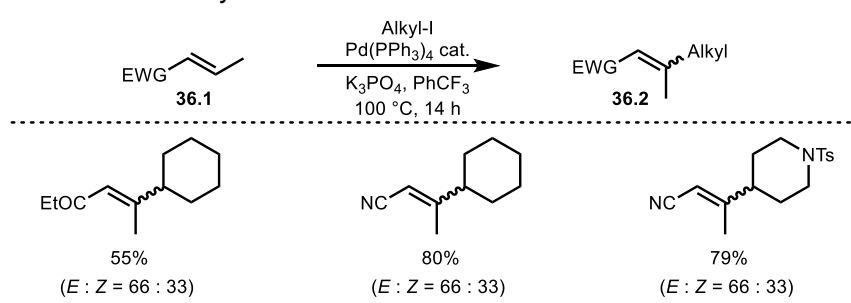

Scheme 36. Alkylation with e-deficient olefins

The reactivities of $(E)$ - and (Z)-olefins are sometimes different from each other. For example, (Z)-enamide 37.1a reacts with a bromomalonate ester possessing a secondary-alkyl moiety to produce $68 \%$ yield of $37.2 \mathrm{a}$ but the reaction with $(E)$-enamide $37.1 \mathrm{~b}$ does not give any products (Scheme 37) [47]. Both of the reactions occur under photo irradiation conditions, and the key intermediate is a radical species generated from the bromomalonate ester. Curiously, the radical species does not appear to react with the $(E)$-olefin at all. In this reaction, bromomalonates possessing a tertiary-alkyl moiety can also react with $(E)-37.1$ in good yield with perfect $(E)$-selectivities. On the other hand a tertiary alkyl group, 1-bromoadamantane, reacts with $\beta$-methylstyrene $\mathbf{3 8 . 1}$ to produce $\mathbf{3 8 . 2}$ in a moderate $15 \%$ yield with perfect $(E)$-selectivity (Scheme 38 ) [48]. Unlike the photoredox system in Scheme 37 , a simple $\mathrm{Pd}$ catalyst system is generally not suitable for alkylation of a internal olefin.

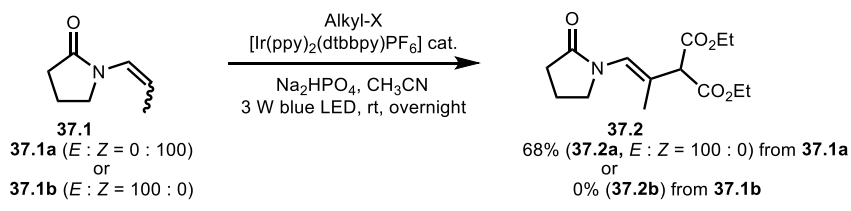

Scheme 37. Alkylation with enamide

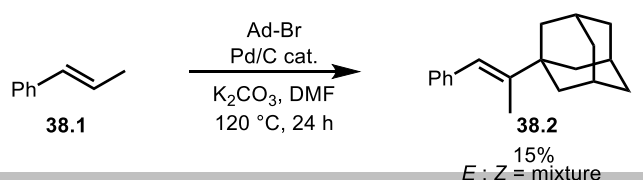




\section{Scheme 38. Tertiary alkylation}

To obtain stereoselective and high yielding alkylation reactions, a directed $\mathrm{C}-\mathrm{H}$ alkylation is one of the few successful methodologies. This is out of main focus of this review, but the concept is illustrated by the example shown (Scheme 39). The reaction of alkenes $\mathbf{3 9 . 1}$ possessing an 8-quinolylamide group as the directing group and alkyl tosylates in the presence of an iron catalyst give the corresponding (Z)-alkylated products $\mathbf{3 9 . 2}$ in good yield with perfect selectivity (Scheme 39) [49].
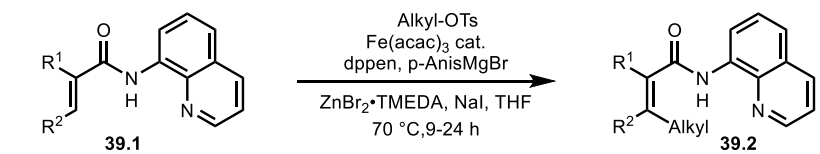

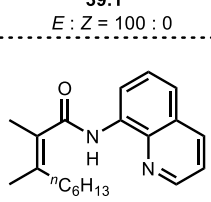

$85 \%$

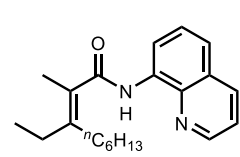

$87 \%$

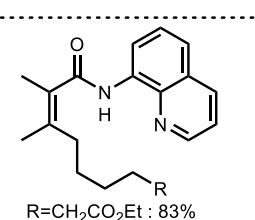

$\mathrm{R}=\mathrm{CH}_{2} \mathrm{CO}_{2} \mathrm{Et}: 83 \%$
Scheme 39. Selective C-H alkylation

\section{Conclusion}

In this review, we have summarized selected examples of the $\mathrm{M}-\mathrm{H}$ reaction with less reactive internal olefins. The $\mathrm{M}-\mathrm{H}$ reaction with a terminal olefin widely employed for the synthesis of trans internal olefins, but the corresponding reactions of internal olefins suffer from low reactivity and poor selectivity. Based on the reaction mechanism of the $\mathrm{M}-\mathrm{H}$ reaction, trans internal olefins should give E-products and cis internal olefins should give Z-products. This can be explained by using a Newman projection of the corresponding carbometallated intermediate, which is generated from the reaction of R-M-X and an olefin. In the case of the arylative $\mathrm{M}-\mathrm{H}$ reaction, most of the cases have employed trans olefins to give products with good to perfect $(E)$ selectivity. The corresponding alkylative reactions, however, have a tendency to result in low yields of the products poor selectivity. Moreover, convergent $\mathrm{M}-\mathrm{H}$ reactions with $E$ and $Z$ mixed olefins have not yet been established in either case. This remains one of the key outstanding challenges in this research area.

\section{Acknowledgements}

We warmly thank YU Project for Formation of the Core Research Centre and JSPS KAKENHI [Grant Number JP 18H04262(TN); Precisely Designed Catalysts with Customized Scaffolding].
Keywords: Mizoroki-Heck reaction - internal olefins - C-C bond formation • stereoselectivity $\cdot$ polysubstituted olefins

[1] a) D. Kurandina, P. Chuentragool, V. Gevorgyan, Synthesis, 2019, 51 985-1005; b) M. Oestreich, The Mizoroki-Heck Reaction; John Wiley \&Sons: Chichester, 2009; c) S. J. Gharpure, Y. G. Shelke, S. R. B. Reddy, RSC Adv. 2014, 4, 46962-46965; d) A. de Meijere, F. E. Meyer, Angew. Chem. Int. Ed. 1994, 33, 2379-2411; e) R.F. Heck, Pure Appl. Chem. 1978, 50, 691-701.

[2] T. Mizoroki, K. Mori, A. Ozaki, Bull. Chem. Soc. Jpn. 1971, 44, 581.

[3] R. F. Heck, J. P. Nolley, J. Org. Chem. 1972, 37, 2320-2322.

[4] Reaction with an organomercury reagent instead of an organic halide: a) R. F. Heck, J. Am. Chem. Soc. 1968, 90, 5535-5538; b) R. F. Heck, J. Am. Chem. Soc. 1969, 91, 6707-6714.

[5] C. C. C. Johansson Seechurn, M. O. Kitching, T. J. Colacot, V. Snieckus, Angew. Chem. Int. Ed. 2012, 51, 5062-5085.

[6] J. Yu, M. J. Gaunt, J. B. Spencer, J. Org. Chem. 2002, 67, 4627-4629.

[7] A. S. Batsanov, J. P. Knowles, A. Whiting, J. Org. Chem. 2007, 72, 2525-2532

[9] A. F. Littke, G. C. Fu, J. Am. Chem. Soc. 2001,123, 6989-7000.

[10] L. Botella, C. Nájera, J. Org. Chem. 2005, 70, 4360-4369.

[11] S. Yu, Z. Zhang, Z. Yu, Y. Shang, Appl. Organometal. Chem. 2014, 28 , 657-660

[12] J. H. Song, T. Kim, J. W. Lee, S.-Y. Moon, W.-S. Kim, J. Ham, Adv Synth. Catal. 2013, 355, 2459-2465.

[13] P. M. Murray, J. F. Bower, D. K. Cox, E. K. Galbraith, J. S. Parker, J. B. Sweeney Org. Process Res. Dev. 2013, 17, 397-405.

[14] H.-J. Xu, Y.-Q. Zhao, X.-F. Zhou J. Org. Chem. 2011, 76, 8036-8041.

[15] D. Xu, C. Lu, W. Chen Tetrahedron 2012, 68, 1466-1474.

[16] a) M. T. Reetz, E. Westermann Angew. Chem. Int. Ed. 2000, 39, 165 168; b) D. Astruc, Inorg. Chem. 2007, 46, 1884-1894.

[17] V. Calò, A. Nacci, A. Monopoli, P. Cotugno Angew. Chem. Int. Ed. 2009 48, 6101-6103.

[18] D. Sharma, S. Kumar, A. K. Shil, N. R. Guha, Bandna, P. Das Tetrahedron Lett. 2012, 53, 7044-7051.

[19] R. Berninia, S. Cacchi, I. De Salveb, G. Fabrizi Synlett, 2006, 18, $2947-$ 2952

[20] D. B. Baker, P. T. Gallagher, T. J. Donohoe, Tetrahedron 2013, 69, 3690-3697

[21] A. Battace, M. Feuerstein, M. Lemhadri, T. Zair, H. Doucet, M. Santelli Eur. J. Org. Chem. 2007, 19, 3122-3132.

[22] M. R. Smith, Y. J. Jang, J. Y. Kim, M. A. Ciufolini, Tetrahedron 2013, 69, 10139-10151.

[23] T. Fukuyama, M. Arai, H. Matsubara, I. Ryu, J. Org. Chem. 2004, 69, 8015-8107.

[24] I. Alonso, J. C. Carretero, J. Org. Chem. 2001, 66, 4453-4456.

[25] D. G. Bachmann, C. C. Wittwer, D. G. Gillingham, Adv. Synth. Catal. 2013, 355, 3703-3707.

[26] R. N. Khanizeman, E. Barde, R. W. Bates, A. Guérinot, J. Cossy, Org Lett. 2017, 19, 5046-5049.

[27] F.-L. Yang, X.-T. Ma, S.-K. Tian, Chem. Eur. J. 2012, 18, 1582-1585

[28] J. C. Pastre, C. R. D. Correia, Adv. Synth. Catal. 2009, 351, 1217-1223.

[29] J. G. Taylor, C. R. D. Correia, J. Org. Chem. 2011, 76, 857-869.

[30] A. Yamamoto, J. Organomet. Chem. 1995, 500, 337-348.

[31] K. Itami, T. Nokami, Y. Ishimura, K. Mitsudo, T. Kamei J. Yoshida, J. Am. Chem. Soc. 2001, 123, 11577-11585.

[32] K. Itami, M. Mineno, N. Muraoka, J. Yoshida, J. Am. Chem. Soc. 2004 126, 11778-11779.

[33] S. Oi, K. Sakai, Y. Inoue, Org. Lett. 2005, 7, 4009-4011.

[34] P. Nilsson, M. Larhed, A. Hallberg, J. Am. Chem. Soc. 2001, 123, 8217-8225.

[35] P. Mauleón, I. Alonso, J. C. Carretero, Angew. Chem. Int. Ed. 2001, 40, 1291-1293. 
[36] a) R. F. Heck, J. Am. Chem. Soc. 1968, 90, 5518-5526; b) C. S. Cho, S. Uemura, J. Organomet. Chem. 1994, 465, 85-92.

[37] Z. He, B. Wibbeling, A. Studer, Adv. Synth. Catal. 2013, 355, 36393647.

[38] Z. He, S. Kirchberg, R. Fröhlich, A. Studer, Angew. Chem., Int. Ed. 2012, 51, 3699-3701.

[39] X. Du, M. Suguro, K. Hirabayashi, A. Mori, T. Nishikata, N. Hagiwara, K. Kawata, T. Okeda, H. F. Wang, K. Fugami, M. Kosugi, Org. Lett. 2001, 3, 3313-3316

[40] Y. Liu, D. Li, C.-M. Park, Angew. Chem., Int. Ed. 2011, 50, 7333-7336.

[41] J. Ruan, X. Li, O. Saidi, J. Xiao, J. Am. Chem. Soc. 2008, 130, 2424 2425.

[42] a) V. N. Zudin, V. D. Chinakov, V. M. Nekipelov, V. A. Rogov, V. A. Likholobov, Y. I. Yermakov, J. Mol. Catal. 1989, 52, 27-48; b) V. V. Grushin, Chem. Rev. 1996, 96, 2011-2034.

[43] K. Hirabayashi, J. Ando, J. Kawashima, Y. Nishihara, A. Mori, T. Hiyama, Bull. Chem. Soc. Jpn. 2000, 73, 1409-1417.
[44] a) Y. Ikeda, T. Nakamura, H. Yorimitsu, K. Oshima, J. Am. Chem. Soc 2002, 124, 6514-6515; b) J. Terao, N. Kambe, Bull. Chem. Soc. Jpn 2006, 79, 663-672; c) L. Firmansjah, G. C. Fu, J. Am. Chem. Soc. 2007, 129, 11340-11341; d) W. Zhou, G. An, G. Zhang, J. Han, Y. Pan Org. Biomol. Chem. 2011, 9, 5833-5837; e) K. S. Bloome, R. L. McMahen, E. J. Alexanian, J. Am. Chem. Soc. 2011, 133, $20146-$ 20148.

[45] W. Liu, L. Li, Z. Chen, C.-J. Li, Org. Biomol. Chem. 2015, 13, 61706174.

[46] C. M. McMahon, E. J. Alexanian, Angew. Chem., Int. Ed. 2014, 53, 5974-5977.

[47] H. Jiang, C. Huang, J. Guo, C. Zeng, Y. Zhang, S. Yu, Chem. Eur. J. 2012, 18, 15158-15166.

[48] S. Bräse, B. Waegell, A. de Meijere, Synthesis 1998, 2, 148-152.

[49] L. Ilies, T. Matsubara, S. Ichikawa, S. Asako, E. Nakamura, J. Am. Chem. Soc. 2014, 136, 13126-13129. 


\section{REVIEW}

Text for Table of Contents

((Insert TOC Graphic here))
Yusei Nakashima, Goki Hirata, Tom D. Sheppard*, and Takashi Nishikata*

Page No. - Page No.

The Mizoroki-Heck reaction with internal olefins: Reactivities and stereoselectivities

Layout 2:

REVIEW

((Insert TOC Graphic here))

Text for Table of Contents
Yusei Nakashima, Goki Hirata, Tom D. Sheppard*, and Takashi Nishikata*

Page No. - Page No.

The Mizoroki-Heck reaction with internal olefins: Reactivities and stereoselectivities 